Oficinas de vídeo pelo celular: o uso, a produção de vídeos e suas possibilidades de utilização como ferramenta pedagógica na educação básica. Revista Ensaios, vol. 15, jul-dez de 2019.

\title{
Oficinas de vídeo pelo celular: o uso, a produção de vídeos e suas possibilidades de utilização como ferramenta pedagógica na educação básica.
}

\author{
Eric de Almeida Fenelon Delphim Tavares ${ }^{1}$
}

Resumo: O objetivo deste artigo é apresentar e debater o uso de celulares e a produção de vídeos através dos recursos desses aparelhos e pensar de que maneira essa produção pode contribuir na construção de aulas dinâmicas. Também se apresenta como podem favorecer o aprendizado dos conteúdos da disciplina de Sociologia por parte dos alunos, discutindo as possibilidades de utilização dessa tecnologia como ferramenta pedagógica. Para efeito de análise, tomarei como base algumas experiências de oficinas e produção de vídeos que realizei durante minha trajetória acadêmica.

Palavras-chave: Audiovisual; TIC na Educação; Telefone Celular; Educação Básica; Ensino de Sociologia.

\section{Mobile video workshops: the use, production of videos and their possibilities of use as a pedagogical tool in basic education.}

\begin{abstract}
The purpose of this article is to present and discuss the use of mobile phones and video production through the capabilities of these devices and to think about how this production can contribute to the construction of dynamic classes. This means that they favor the learning of the contents of the Sociology subject by the students. The main purpose of the paper is therefore to discuss the possibilities of using this technology as a pedagogical tool. For analysis purposes, I will use as a base some experiences of workshops and vídeo production that I made during my academic career.
\end{abstract}

Keywords: Audiovisual; ICT in Education; Cellular Phone; Basic Education; Sociology Teaching.

\footnotetext{
${ }^{1}$ Licenciado Ciências Sociais pela Universidade Federal Fluminense (UFF). Brasil, Niterói, Rio de Janeiro. ericfenelon@id.uff.br.
} 
Oficinas de vídeo pelo celular: o uso, a produção de vídeos e suas possibilidades de utilização como ferramenta pedagógica na educação básica. Revista Ensaios, vol. 15, jul-dez de 2019.

O objetivo deste artigo é apresentar e debater o uso de celulares e a produção de vídeos através dos recursos desses aparelhos e pensar de que maneira essa produção pode contribuir na construção de aulas dinâmicas. Também se apresenta como podem favorecer o aprendizado dos conteúdos da disciplina de Sociologia por parte dos alunos, discutindo as possibilidades de utilização dessa tecnologia como ferramenta pedagógica. Para efeito de análise, tomarei como base algumas experiências de oficinas de produção de vídeos que realizei durante minha trajetória acadêmica.

Para refletir sobre o uso das Tecnologias da Informação e da Comunicação (TICs) de maneira pedagógica, é preciso pensar a importância dessa utilização na educação escolar e na disciplina de sociologia, uma vez que as TICs fazem parte do cotidiano escolar e da sociedade atual. Dessa forma, cabe ao professor, desde sua formação, se apropriar tecnicamente dessas ferramentas e incentivar os estudantes a utilizarem essas tecnologias de maneira reflexiva. Assim como Mello (2017, p. 168) explica, "em um mundo como esse, defendo que não é possível estimular os jovens a pensarem sociologicamente a cidadania, o trabalho, a cultura e a socialização sem a mediação dos TICs".

Portanto, discutirei ao longo do artigo a utilização dessa tecnologia como ferramenta pedagógica. Na primeira, parte faço uma breve discussão sobre a tecnologia do aparelho celular. Na segunda, apresento os precedentes que deram origem a construção do trabalho, as justificativas, os objetivos e os procedimentos metodológicos. Por último, apresento o universo da pesquisa e as oficinas de produção de vídeo pelo celular, assim como as considerações finais da pesquisa.

\section{1) TICs e o uso de celulares:}

O surgimento, o desenvolvimento e o impacto das TICs na educação fazem parte das transformações dessas tecnologias na sociedade. Historicamente, as TICs têm início com o cinema, que no começo do século XX já era reconhecido como recurso pedagógico complementar, e como uma uma forma alternativa capaz de interferir na educação das massas longe dos bancos escolares (DUARTE; ALEGRIA, 2013). 
Oficinas de vídeo pelo celular: o uso, a produção de vídeos e suas possibilidades de utilização como ferramenta pedagógica na educação básica. Revista Ensaios, vol. 15, jul-dez de 2019.

A partir da terceira Revolução Industrial, que teve início na década de 1950 e vem se intensificando até os dias de hoje, a eletrônica modernizou a indústria mundial e com ela surgem os computadores e seus recursos, como os softwares, hardware e a web. Com o avanço tecnológico da informação, decorrente do surgimento desta revolução, diversos campos do conhecimento sofreram mudanças no âmbito econômico, social e político. Com isso, a sociedade alterou sua forma de organização, produção e interação social entre os indivíduos, tal como dizem Coll e Monereo (2010, p.16):

Ao surgimento de uma nova forma de organização econômica, social, política e cultural, identificada como sociedade da informação (SI), que comporta novas maneiras de trabalhar, de comunicar-se, de relacionarse, de aprender, de pensar e, em suma, de viver. O fato significativo é que essa nova sociedade se sustenta, em grande medida, no desenvolvimento espetacular das TICs durante a segunda metade do século XX. Como consequência desse desenvolvimento, estaríamos, nas palavras de Castells (2000, p. 60), diante de um "novo paradigma tecnológico, organizado em torno das tecnologias da informação" e associado a profundas transformações sociais, econômicas e culturais.

Instrumentos como a televisão, o computador e o celular integram mudanças em nossos modos de produção de conhecimento, e a forma como se manifestam no âmbito da comunicação e da educação escolar. Neste trabalho, no entanto, nos limitaremos à análise do uso dos celulares, já que esta expansão atinge sobretudo os adolescentes e jovens, contribuindo para uma nova forma de apropriação e manipulação dos recursos dessas tecnologias. Assim como analisa Labrunie e Ferreira(2018, p. 4):

Uma decorrência marcante da expansão do acesso a tecnologias digitais é o convívio, cada vez maior, das pessoas com um grande número e repertório de imagens e textos multimodais. As câmeras digitais e smartphones (que integram câmeras fotográficas de qualidade progressivamente melhor) conectados em rede possibilitaram uma disseminação sem paralelo na história de registros audiovisuais do cotidiano das pessoas que fotografam, filmam e circulam suas produções quase que instantaneamente.

Nesse sentido, busco, através de algumas experiências de oficinas e produção de vídeos que realizei durante minha trajetória acadêmica, explicitar e fundamentar esse recurso como ferramenta pedagógica. Como formas tanto de construção e valorização de narrativas, quanto para apreender as realidades de modo mais crítico, sob os pilares do estranhamento e conseguir elaborar reflexões próprias sobre os veículos midiáticos e a forma como eles leem determinadas realidades. E, portanto, demonstrar como a produção 
Oficinas de vídeo pelo celular: o uso, a produção de vídeos e suas possibilidades de utilização como ferramenta pedagógica na educação básica. Revista Ensaios, vol. 15, jul-dez de 2019.

de vídeos através dos recursos desses aparelhos podem contribuir na mediação didática dos conteúdos e que valorizam o conteúdo programático e os conhecimentos dos alunos (MELLO, 2017, p. 173).

\section{2) Trajetórias:}

Para fundamentar esse artigo, apresento os antecedentes que deram origem à construção do objeto de pesquisa. Entre os anos de 2012 e início de 2018, fiz parte do Curso de Comunicação Popular do Núcleo Piratininga de Comunicação (NPC). O curso de comunicação popular é realizado no Rio de Janeiro e existe há mais de dez anos. Ele é voltado para moradores de favelas, militantes sociais, estudantes de comunicação, sindicalistas e demais interessados. A divulgação para seleção dos novos estudantes acontece por indicações dos ex-alunos, pelo site e boletim de notícias do NPC e convites enviados por e-mail. Financiado pela Fundação Rosa Luxemburgo, o curso é gratuito e ocorre todo ano, de março a novembro, aos sábados, de 15 em 15 dias e oferece aulas tanto teóricas quanto práticas, que auxiliam na formação dos alunos para o amplo mundo da comunicação hoje.

Segundo o livro do NPC (2016, p. 21):

O objetivo principal é fazer com que cada aluno se transforme em um multiplicador dessa ideia, contribuindo ou criando veículos de comunicação nas localidades em que moram e/ou nos movimentos em que atuam. Como queremos cada vez mais gente divulgando sua visão de mundo, para nós, quanto mais gente estiver pensando, escrevendo e falando, melhor.

Dessa forma, pensar a comunicação popular é pensar a comunicação feita coletivamente pelos moradores de favelas ou bairros populares que tenham interesses em comum, para que sejam porta-vozes dos interesses da comunidade em que estão inseridos, e para que também possam auxiliar a comunidade a se organizar em torno de seus problemas. É a comunicação que fala do dia a dia da comunidade a partir do olhar de quem a produz e vive este dia a dia. 
Oficinas de vídeo pelo celular: o uso, a produção de vídeos e suas possibilidades de utilização como ferramenta pedagógica na educação básica. Revista Ensaios, vol. 15, jul-dez de 2019.

Durante o curso, aprendemos a importância de produzirmos uma mídia contra hegemônica para contribuir com a construção de um mundo mais justo. Para atingir este objetivo, são elaboradas as aulas práticas sobre uso da internet, mídias digitais, webradio, rádio, redação, diagramação e edição de vídeos. No final do curso é criado o jornal Vozes das Comunidades, que é a materialização de todo o processo de aprendizagem ao longo do tempo de curso.

Este curso despertou a vontade de produzir vídeos de maneira crítica. Durante as jornadas de junho de $2013^{2}$, ao participar dos protestos, percebi um aumento expressivo na produção audiovisual de grupos independentes (202 produções, Mídia Ninja, por exemplo), e senti necessidade de registrar esse fenômeno. Gravando com uma câmera de baixa qualidade, esse material deveria ir para uma ilha de edição, mas como não tinha um computador para isso, acabou ficando guardado num hd externo para uma possível edição.

Em 2014, continuei no curso de comunicação popular, não como aluno, mas contratado como funcionário do Núcleo Piratininga de Comunicação. Uma das minhas funções era a organização e produção do curso. No primeiro encontro da turma de 2014, foi feita uma roda de conversa e fizemos um pequeno balanço das jornadas de junho do ano anterior. Minha fala foi em torno da necessidade e importância do audiovisual, devido à quantidade de visualizações pela internet em comparação aos textos, sendo bem maiores.

Nesse mesmo ano, no mês de março, produzi meu primeiro vídeo com os recursos do Núcleo Piratininga de Comunicação, a câmera e um computador que usamos como ilha de edição. O vídeo chamado Homenagem à Ocupação Manuel Congo ${ }^{3}$ retrata os moradores da referida ocupação, localizada ao lado da Câmara dos Vereadores, no Centro do Rio, recebendo a Medalha Popular Manuel Congo. A entrega aconteceu nas

\footnotetext{
${ }^{2}$ As Jornadas de junho foi uma série de manifestações de rua que ocorreu nas principais capitais do país. Esses protestos surgiram contra os aumentos nas tarifas de transporte público. Mais informações: <https://www.nexojornal.com.br/expresso/2017/06/17/O-que-foram-afinal-as-Jornadas-de-Junho-de2013.-E-no-que-elas-deram>. Acesso em: 02 jun. 2019.

3 Homenagem à Ocupação Manuel Congo. Disponível em:
$<$ https://www.youtube.com/watch?v=xxqH5TbL99s $>$. Acesso em: 02 jun. 2019.
} 
Oficinas de vídeo pelo celular: o uso, a produção de vídeos e suas possibilidades de utilização como ferramenta pedagógica na educação básica. Revista Ensaios, vol. 15, jul-dez de 2019.

escadarias da Câmara na Cinelândia e foi uma iniciativa do mandato do vereador Renato Cinco do PSOL.

Essa homenagem surgiu após a tentativa de entrega da Medalha Pedro Ernesto à Ocupação. Mas a medalha foi vetada em sessão na Câmara de Vereadores ${ }^{4 ;}$ os argumentos foram em defesa da propriedade privada e a não destinação de prédios públicos abandonados à habitação popular, além de serem contra os movimentos de luta pela moradia, os vereadores se negaram a entregar a maior homenagem que a Câmara oferece.

Há anos as ocupações urbanas são alvos de críticas de grupos conservadores. Para esses grupos, tais ocupações apropriam-se de terra particular e isso viola o princípio da propriedade privada. Segundo moradores, a ocupação é exemplo de como um prédio público abandonado pode ser transformado em habitação popular. O edifício em questão foi adquirido pelo Fundo Nacional de Habitação de Interesse Social (FNHIS) e hoje está sendo reformado com verbas do programa Minha Casa, Minha Vida. Desde 2014, a Medalha Popular Manuel Congo é conferida para pessoas e movimentos sociais ligados à luta pela moradia, pois reforça a luta pela moradia digna e o direito à cidade.

No mês seguinte, produzi outro vídeo chamado Morro do Bumba: Quatro Anos Depois $^{5}$, que trata da luta dos moradores quatro anos após a destruição causada pelas fortes chuvas. Foram 47 mortos em apenas um dia e diversas famílias ficaram desabrigadas. Esse acontecimento ficou conhecido como Tragédia do Bumba, comunidade com o maior número de vítimas naquele dia.

Com a ajuda de um aluno, o jornalista Daniel Climaco, que trabalhou na edição de vídeos do jornal RJTV, finalizamos o vídeo e o NPC o convidou, então, para participar da edição do documentário Vila Recreio 2: Sonhos Demolidos ${ }^{6}$. O documentário, produzido pelo NPC, conta a história de Jorge Santos, um ex-aluno do curso de comunicação popular e morador da Vila Recreio 2, na Zona Oeste do Rio. Devido à

\footnotetext{
4 Vereadores recusam homenagem à Ocupação Manuel Congo. Disponível em: <http://renatocinco.com/teste/?p=1920>. Acesso em: 02 jun. 2019.

5 Morro do Bumba: Quatro Anos Depois. Disponível em: <https://www.youtube.com/watch?v=vKkwuWjrPNA $>$. Acesso em: 03 jun. 2019.

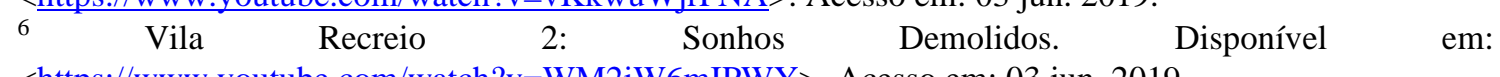
<https://www.youtube.com/watch?v=WM2iW6mIPWY>. Acesso em: 03 jun. 2019.
} 
Oficinas de vídeo pelo celular: o uso, a produção de vídeos e suas possibilidades de utilização como ferramenta pedagógica na educação básica. Revista Ensaios, vol. 15, jul-dez de 2019.

construção da Transoeste, a comunidade onde residia foi uma das atingidas pelo processo de remoções que aconteceu no Rio de Janeiro, desde a realização da Copa do Mundo e das Olimpíadas no Rio.

Além do documentário, o jornalista Daniel Climaco foi convidado para ministrar as aulas de audiovisual do curso de comunicação popular junto comigo. No sábado, dia 21 de maio, realizamos uma oficina de vídeo reportagem no auditório do SINDPETRO/RJ que contou com a presença de 20 alunos selecionados no mês de fevereiro ${ }^{7}$.

Pela manhã, o professor Climaco ensinou o processo de produção de uma vídeo reportagem. Apresentou a parte técnica e de produção, os elementos como off, sonora, passagem. Noções básicas de enquadramento e iluminação. Também falou de como é preciso pensar as notícias que vão compor os vídeos e seus critérios; são estes que vão determinar como e quando a notícia entra no vídeo. A preocupação com a imagem está presente desde a pauta.

Como atividade, foi proposto que a turma se dividisse em grupos e começassem a produzir vídeos sobre a Copa do Mundo. Dessa produção, surgiram três documentários. O primeiro, chamado Sobrou Pra Quem $?^{8}$, retrata um protesto na praia de Copacabana contra a copa do mundo, no dia 28 de junho de 2014. O segundo traz as opiniões de moradores sobre a copa em uma rua que foi fechada e enfeitada para que os moradores assistissem os jogos juntos e foi chamado de Comemorar o que $?^{9}$. O terceiro, chamado SMH - Saia do Morro Hoje ${ }^{10}$, fala das remoções tanto de moradores que saíram de suas casas e foram destinados para conjuntos habitacionais do projeto Minha Casa, Minha

\footnotetext{
${ }^{7}$ Publicação do site do Núcleo Piratininga sobre a nona edição, em 2014, do Curso de Comunicação Popular do NPC. Mais informações em: <http://nucleopiratininga.org.br/curso-de-comunicacao-popular-comecadia-15-de-marco/>. Acesso em: 03jun2019.

${ }^{8}$ Sobrou Pra Quem?. Disponível em: <https://www.youtube.com/watch?v=8utIzQnSikM. Acesso em: 03 jun. 2019.

${ }^{9}$ Comemorar o que?. Disponível em: <https://www.youtube.com/watch?v=4OOL0GAf8zM. Acesso em: 03 jun. 2019.

${ }^{10}$ SMH - Saia do Morro Hoje. Disponível em: <https://www.youtube.com/watch?v=dPCkXlCMAok. Acesso em: 03 jun. 2019.
} 
Oficinas de vídeo pelo celular: o uso, a produção de vídeos e suas possibilidades de utilização como ferramenta pedagógica na educação básica. Revista Ensaios, vol. 15, jul-dez de 2019.

Vida, quanto daqueles que decidiram ficar, não abandonando seus locais de origem e promovendo uma resistência.

Nesse ano, o NPC decidiu produzir um documentário que falasse das experiências em comunicação popular na cidade do Rio de Janeiro. A ideia era falar dos jornais e programas de rádio e de televisão produzidos por moradores de diversas comunidades, como o Morro do Borel, o conjunto de favelas da Maré, Santa Marta, Rocinha. Daí surge Comunicação Popular no Rio: Quem faz ${ }^{11}$. O filme, concluído no início de 2015, apresenta também o curso de formação de comunicadores populares do NPC. Esse documentário serve de inspiração para o livro do NPC citado acima.

Apesar da produção desses filmes ter sido feita com equipamentos do NPC, tanto a câmera, quanto os computadores para ilha de edição, algumas imagens foram feitas com celular. Percebemos, então, que a maioria dos alunos não tinha recursos para a compra de equipamentos, câmera para filmar e computadores para editar. Daí, sugeri que no próximo ano era necessário optarmos pelo celular durante as oficinas de vídeo como recurso para o audiovisual. Isso porque, devido seu barateamento no mercado, o uso dos celulares atingiu quase todas as faixas etárias na sociedade, em especial os adolescentes e jovens. O fato de conectar todos em redes sociais trouxe novas formas de utilização dessa tecnologia. Assim, o celular é uma ferramenta que fotografa, filma e registra o cotidiano das pessoas, além de circular essas produções quase instantaneamente pela web (LABRUNIE; FERREIRA, 2018).

Devido o falecimento do coordenador geral do NPC, Vito Giannotti, no ano de 2015 , não conseguimos prosseguir com esse projeto. No intervalo de um ano, devido aos avanços tecnológicos, descubro um aplicativo de edição para celular chamado Kinemaster $^{12}$. Com ele, é possível editar as imagens captadas pelo aparelho telefônico. Assim, atualmente, o celular se tornou uma das ferramentas na construção de comunicação contra-hegemônica e, com ele na mão, podemos nos tornar protagonistas da nossa realidade; não só dar as notícias como nós as vivemos, mas também enxergar as

\footnotetext{
${ }^{11}$ Comunicação Popular no Rio: Quem faz. Disponível em: 〈https://www.youtube.com/watch?v=sSSFvoZzwdQ\&t=46s >. Acesso em: 03 jun. 2019.

${ }^{12}$ KineMaster - Professional Mobile Video Editor. Disponível em: 〈https://www.kinemaster.com/>. Acesso em: 05 jun. 2019.
} 
Oficinas de vídeo pelo celular: o uso, a produção de vídeos e suas possibilidades de utilização como ferramenta pedagógica na educação básica. Revista Ensaios, vol. 15, jul-dez de 2019.

notícias das grandes mídias e dos veículos midiáticos com olhos mais críticos e atentos, podendo contra-argumentar com aspectos que de fato são importantes às nossas realidades.

A partir desse momento, consegui uma independência na produção de vídeos, pois agora era possível fazer filmes sem a necessidade de uma ilha de edição. Ao refletir sobre essa ferramenta, uma TIC, e suas possibilidades pedagógicas nas escolas, pode-se perceber que são dispositivos que quando inseridos e utilizados como forma de construir e de potencializar a mediação didática, auxiliam no processo de ensino aprendizagem e na forma como o aluno constrói o conhecimento e em como o professor repensa sua atividade docente. Ao ser utilizada em sala de aula e ao se relacionar com o processo de ensino, nas palavras de Mello (2017, p. 172),

As TICs podem revolucionar o nosso fazer pedagógico, transformando um cotidiano, para muitos maçante e tedioso, em algo dinâmico e criativo. Acredito que as novas tecnologias de comunicação utilizadas de forma planejada e adequada nas escolas, são importantes recursos para estabelecer diálogos entre os conteúdos programáticos estabelecidos nas grades curriculares de cada disciplina e uma aprendizagem prazerosa em sala de aula, com objetivo de formar cidadãos instruídos e críticos, estimulando-os para perceber aspectos significativos para sua vida presente e futura.

Em meados de 2016, ministramos a oficina de vídeo pelo celular. A oficina contou com a presença de mais de 20 alunos e aconteceu novamente no auditório do SINDPETRO/RJ. Partindo de noções básicas e úteis, tanto à câmera quanto ao celular, foram apresentados para os alunos alguns acessórios para o celular, como microfones de lapela e lentes externas. Após essa apresentação,e pensando na independência em relação ao fazer técnico, os alunos aprenderam como fazer um suporte de câmera e de celular numa tampa de refrigerante.

Em seguida, a turma foi dividida em grupos que começaram a produzir vídeos pelo celular, da gravação à edição. Apenas um vídeo foi concluído, chamando Que é Ser Mulher ${ }^{13}$, onde os alunos entrevistam as mulheres do curso fazendo a pergunta que leva

13 Que é Ser Mulher? Disponível em:
〈https://www.youtube.com/watch?v=dptfVSW4Ys0\&list=PL2OAzE7y8BOavbXXyPDvdpD4As8tuSY1 3\&index=23>. Acesso em: 05 jun. 2019. 
Oficinas de vídeo pelo celular: o uso, a produção de vídeos e suas possibilidades de utilização como ferramenta pedagógica na educação básica. Revista Ensaios, vol. 15, jul-dez de 2019.

o nome do vídeo. Todos os vídeos produzidos estão disponíveis no canal do youtube do Núcleo Piratininga de Comunicação ${ }^{14}$.

Participar e construir com a equipe do NPC, sobretudo do curso de Comunicação Popular, foi fundamental para que eu começasse a realizar as oficinas de vídeo pelo celular com os alunos do ensino público. O ponto de partida para essa inserção foi através de convites que recebi de algumas escolas, como o Colégio Estadual Paulo Assis Ribeiro (CEPAR), ocupado pelos estudantes em Niterói no ano de 2016, e o Colégio Estadual Paulino Barbosa, feita no ano de 2017 em Belford Roxo na atividade da escola nomeada Feira Integrada Cultivando Valores: Eu respeito, e você?. Refletirei sobre as experiências das oficinas nessas escolas a seguir.

Para conseguir estabelecer essa ferramenta num formato escolar, e que valorizasse os passos do projeto, esse conhecimento teve de passar pelos três níveis de transformação de uma transposição didática.

Segundo os estudos de Geraldo Almeida (2007), o termo transposição didática foi exposto por Michael Verret no ano de 1975. Mas o trabalho de Yves Chevallard ampliou o conceito ao estabelecer três estágios de transformação: o primeiro estágio é o Saber Sábio, elaborado pelo conhecimento científico; o segundo seria o Saber Ensinar, relacionado à didática, ou seja, é o conhecimento a ser ensinado se transforma em conhecimento efetivamente ensinado; e o terceiro, o Saber Ensinado, que é o conhecimento elaborado pelos cientistas, transposto pelo professor e reelaborado pelo estudante (ALMEIDA, 2007, p. 10). Assim, esse processo característico da transposição didática nos revela que qualquer conhecimento para ser ensinado necessita de um encontro estabelecido entre o fazer e o aprimorar, a fim de tornar a atividade não só didática em sua execução, mas prioritariamente adaptável e capaz de gerar autonomia de pensamento e reelaboração para o estudante.

Portanto, a partir desse momento, buscamos conciliar o material audiovisual produzido em campo durante as oficinas com bibliografias que nos auxiliam na

14 Canal do youtube do Núcleo Piratininga de Comunicação. Disponível em: <https://www.youtube.com/playlist?list=PL2OAzE7y8BOavbXXyPDvdpD4As8tuSY13>. Acesso em: 07 jun. 2019. 
Oficinas de vídeo pelo celular: o uso, a produção de vídeos e suas possibilidades de utilização como ferramenta pedagógica na educação básica. Revista Ensaios, vol. 15, jul-dez de 2019.

compreensão, tanto da importância da apropriação das TICs em sala de aula quanto na necessidade de alinhar essa tecnologia a sociologia escolar e trazer ao aluno uma autonomia em relação a sua própria realidade, para além dos muros da escola.

\section{3) Oficinas nas escolas:}

\section{1) Escolas ocupadas: o caso CEPAR.}

Quando fiz minha primeira visita, no primeiro semestre de 2016, diversas escolas da Rede Estadual de Educação estavam ocupadas por estudantes no Rio de Janeiro. Contra os cortes de verbas e privatizações na educação, os secundaristas iniciaram uma série de ocupações, chegando ao número de 80 escolas ocupadas.

Em Niterói foram cinco escolas ocupadas. O Instituto de Educação Professor Ismael Coutinho (IEPIC), localizado no bairro de São Domingos, foi o primeiro na cidade, no dia 07 de abril. No bairro do Badu, o Colégio Estadual Paulo Assis Ribeiro (CEPAR) foi ocupado em 13 de abril. Além desses, o Colégio Estadual David Capistrano (CEDC), localizado em Santa Bárbara, foi ocupado no dia 12 de abril. Mais à frente, em 10 de maio, o Colégio Estadual Pinto Lima (CEPLIM) localizado no centro da cidade, incorporou, também, o movimento, nesse mesmo dia houve ainda a ocupação do Colégio Estadual Leopoldo Fróes (CELF), no bairro do Largo da Batalha. (BARRETO, 2016, p. 77).

Nesse período, fui convidado para fazer uma oficina no Colégio Estadual Paulo Assis Ribeiro (CEPAR) pelo Centro de Mídia Independente (CMI). Durante as ocupações na cidade de Niterói, este grupo de mídias ativistas acompanhou as ocupações e o material consta em sua página no youtube $e^{15}$. Assim que cheguei na escola, percebi que o CMI tinha uma entrada na organização estudantil, pois os grupos de mídia hegemônica não tinham permissão para frequentar aqueles espaços e o CMI era quem "mostrava ao mundo quem eles eram realmente", segundo o relato de um aluno, ao chegar no CEPAR.

A ideia da oficina era dar aos estudantes autonomia na produção de vídeos, pois havia grupos de estudantes contra as ocupações. Dessa forma, desenvolver nos estudantes

\footnotetext{
${ }^{15}$ Página do youtube do Centro de Mídia Independente (CMI). Disponível em: <https://www.youtube.com/user/midiaindependente/videos $>$. Acesso em: 10 jun. 2019.
} 
Oficinas de vídeo pelo celular: o uso, a produção de vídeos e suas possibilidades de utilização como ferramenta pedagógica na educação básica. Revista Ensaios, vol. 15, jul-dez de 2019.

essa apropriação com as Tecnologias de Informação e Comunicação (TIC) era importante, principalmente nesse contexto de ocupação escolar. Uma vez que ensinar não é somente transmitir conhecimentos, meu papel como educador naquele momento era estimular a curiosidade e a autonomia dos jovens para a própria segurança deles.

Os estudantes informaram que, muitas vezes, os desocupas mentiam sobre a forma como eles se organizavam e agiam de forma violenta para acabar com a ocupação. A expectativa deles com a oficina era justamente ter a possibilidade de apresentar suas próprias versões sobre o que efetivamente acontecia dentro da escola ocupada e difundir pelas redes sociais. A principal rede era a página no Facebook chamada \#OcupaCEPAR. Assim, o processo de aprendizagem dos sujeitos a partir das TICs colabora com a constituição da autonomia dos educandos, sua segurança enquanto ocupação e com o estímulo de curiosidades; segundo Freire:

A autonomia, enquanto amadurecimento do ser para si, é processo, é vir a ser. Não ocorre em data marcada. É neste sentido que uma pedagogia da autonomia tem de estar centrada em experiências estimuladoras da decisão e da responsabilidade, vale dizer, em experiências respeitosas da liberdade (FREIRE, 1996, p. 25).

Antes da oficina começar, demos uma volta pela escola, pois os estudantes queriam apresentar a nova casa deles. Durante a visita, haviam poucos alunos na escola, pois na parte da manhã aconteceu uma assembleia e muitos foram até às suas residências buscar material para permanecer na escola ocupada. No momento da visita aconteciam diversas atividades na escola, alguns conversavam, sobre uma das duas mesas de concreto com o fundo de tabuleiro para o jogo de damas ou xadrez, sobre o que aconteceu anteriormente na assembleia. Eles observavam um grupo de alunos que praticavam Slackline ${ }^{16}$ no pátio central da escola.

Enquanto isso, uma roda de conversa localizada no mesmo local da assembleia virou roda de violão. No principal portão de entrada da escola dois alunos faziam a

\footnotetext{
${ }^{16}$ Slackline é um esporte de equilíbrio sobre uma fita elástica esticada entre dois pontos fixos, o que permite ao praticante andar e fazer manobras por cima. Mais informações: <https://pt.wikipedia.org/wiki/Slackline>. Acesso em: 10 jun. 2019.
} 
Oficinas de vídeo pelo celular: o uso, a produção de vídeos e suas possibilidades de utilização como ferramenta pedagógica na educação básica. Revista Ensaios, vol. 15, jul-dez de 2019.

segurança do local, no refeitório alguns preparavam a comida para servir no horário do lanche da ocupação. As refeições servidas eram definidas em quatro horários, café da manhã, almoço, lanche da tarde e jantar.

Eram cerca de 20 alunos dentro da escola e 6 participariam da oficina. Após a visita e a pausa para o lanche, iniciamos a oficina de vídeo pelo celular. Com apenas 2 horas para ser realizada, a oficina aconteceu no auditório da escola e contava com uma TV. Ela possibilitou a apresentação de um power point que produzi para minhas oficinas, com filmes, fotos e textos em seu conteúdo. Assim iniciei a oficina, e o primeiro objetivo era que os alunos compreendessem aquilo que havia aprendido no NPC: a construção de uma comunicação contra-hegemônica.

$\mathrm{Na}$ sequência, expliquei como as grandes empresas de comunicação agem para difundir suas ideias, dados atuais afirmam que cinco famílias controlam metade dos 50 veículos de comunicação com maior audiência no Brasil ${ }^{17}$. Eles difundem sua ideologia através dos seus veículos de comunicação, rádio, TV, redes sociais, etc. Dei como exemplo um vídeo que produzi para o NPC sobre a novela Império ${ }^{18}$. A novela constrói o personagem, líder do movimento sem casa, como um criminoso. Durante a trama, o personagem protagonista, o comendador José Alfredo, um homem milionário que enriquece com os negócios da joalheria Império, e no meio dessa história surge um grupo de ativistas querendo casa, os sem casa. O líder, o personagem Cardoso, é retratado como um vilão pelo autor da novela e aparece pela primeira vez na ocupação de um casarão em Santa Teresa. Após a exibição do vídeo sobre a novela, um dos alunos explanou que a Rede Globo faz a mesma coisa com eles, criminalizando as ocupações estudantis. Todos os estudantes concordaram. Eles citaram exemplos dos noticiários. Aproveitei a brecha no debate para perguntar se poderíamos responder à criminalização produzida por essa grande rede da televisão brasileira com uma comunicação produzida por eles. Novamente

17 Disponível em: <https://www.cartacapital.com.br/sociedade/cinco-familias-controlam-50-dosprincipais-veiculos-de-midia-do-pais-indica-relatorio/>. Acesso em: 10 jun. 2019.

${ }^{18}$ Império é uma telenovela brasileira produzida e exibida pela Rede Globo no horário das 21 horas de 21 de julho de 2014 a 13 de março de 2015, em 203 capítulos. Disponível em: <https://pt.wikipedia.org/wiki/Imp\%C3\%A9rio_(telenovela)〉. Acesso em: 10 jun. 2019. 
Oficinas de vídeo pelo celular: o uso, a produção de vídeos e suas possibilidades de utilização como ferramenta pedagógica na educação básica. Revista Ensaios, vol. 15, jul-dez de 2019.

todos concordaram, e perceberam que já haviam construído algum veículo contra hegemônico ao criarem a página na rede social Facebook.

A proposta para a reflexão final foi que produzissem diversos vídeos usando os próprios recursos, no caso, o celular. Eles mostrariam o dia a dia da ocupação, como o funcionamento da cozinha, a limpeza, a organização da escola, os cartazes dessas organizações, também fariam entrevistas com professores apoiadores. Alguns pensaram em registrar as assembleias, mas concordaram que isso poderia prejudicar a segurança deles. Após esse pequeno debate, percebi que além da compreensão sobre mídia hegemônica e contra-hegemônica, alguns alunos já tinham criado suas próprias estratégias para os registros das imagens em vídeo.

Oferecer essa oficina numa ocupação estudantil, era totalmente diferente das escolas em funcionamento normalizado. A relação dos estudantes com o espaço escolar havia mudado, o sentimento de pertencimento dos estudantes perante à instituição foi de certa forma fortalecido; existia um cuidado da escola. Uma aluna me explicou que "os celulares serviam para uma ocupação dupla, uma dentro da escola e outra pelas redes sociais!". Portanto, ao utilizarem seus aparelhos celulares dentro do espaço escolar para registrarem seu cotidiano, esses registros e as reivindicações do movimento de ocupação eram expostos no ambiente virtual pela página deles do Facebook. Ali, eles filmaram e registraram a falta de condições de funcionamento do CEPAR, divulgaram seus eventos e informações, e fizeram convocações de assembleias comunicando a situação em que se encontrava a escola. Além da divulgação das ações cotidianas de ocupação, os estudantes também solicitaram produtos de higiene e limpeza e doações de alimentos.

Essa autonomia dos estudantes, além da aprendizagem de superação de cada um deles, despertou o interesse em outras pessoas para conhecer suas demandas e fez com que outros estudantes aderissem ao movimento de ocupação. Assim, ajudar a desenvolver esse protagonismo foi importante para autonomia no processo de aprendizagem dos sujeitos dentro desse contexto escolar.

Algo contundente a se pensar sobre a comunicação popular e sobre seus ensinamentos para construção de mediações e valorização de um recurso que vem sendo 
Oficinas de vídeo pelo celular: o uso, a produção de vídeos e suas possibilidades de utilização como ferramenta pedagógica na educação básica. Revista Ensaios, vol. 15, jul-dez de 2019.

criminalizado dentro das salas de aula, parte do esforço de entender como se apropriar do celular como uma ferramenta pedagógica, e o mais importante: o por quê.

Segundo Muniz Sodré (2002, p. 21), há um grande esforço de visibilizar somente o caráter técnico de um dispositivo midiático. Ao se classificar as mídias apenas como meramente instrumentais, como se estivessem descolados de todo o caráter social e que corrobora com a manutenção de uma grande hegemonia, oculta-se o aspecto ideológico por trás de determinadas ferramentas. O que nos faz pensar a comunicação e as estratégias midiáticas para além dos veículos de comunicação, mas sobretudo para formas de organização de discurso que se repetem e se deslocam principalmente fora deles.

Para além disso, nos leva a repensar também o próprio termo comunicação como algo que apenas veículos de comunicação produzem, e a retornar ao ato mais dinâmico de comunicar como uma estratégia comunitária, estratégia essa que não só existe para registrar uma própria realidade, mas sobretudo para estabelecer vínculos críticos com a grande mídia, capazes de identificar de modo mais apropriado quais são as teias hegemônicas e no que elas transformam ou não transformam em notícia e quais seus objetivos com isso.

No caso da ocupação, por exemplo, o que mais me chamou atenção foi o fato dos alunos verem, a partir do próprio processo político de ocupar e suas principais demandas, as suas atuações serem distorcidas por pessoas contrárias ao movimento. E ver essa distorção ser alavancada não só na grande mídia que lançava notícias sobre a ocupação, mas principalmente nas redes sociais, que hoje em dia tem se tornado um veículo ainda mais potente de disseminação de informações sem veracidade. Ampliando e corroborando com a hegemonia vigente de certo modo, distorcendo cada vez mais os fatos e as verdadeiras proposições dos acontecimentos a fim de criar falsas verdades.

Foi um grande exemplo de como a hegemonia nos veículos de comunicação acaba se apropriando de várias outras ferramentas para se maximizar e acaba se embrenhando na nossa vida cotidiana. E que pode e deve ser revidada com formas de comunicar que tanto seja uma crítica ao modelo vigente de disseminação de informação quanto a construção de um novo modelo, simultaneamente. 
Oficinas de vídeo pelo celular: o uso, a produção de vídeos e suas possibilidades de utilização como ferramenta pedagógica na educação básica. Revista Ensaios, vol. 15, jul-dez de 2019.

\section{2) Escolas funcionando normalmente: o caso Colégio Estadual Paulino}

\section{Barbosa.}

No segundo semestre de 2017, o Colégio Estadual Paulino Barbosa localizado na cidade de Belford Roxo produziu uma atividade nomeada Feira Integrada Cultivando Valores: Eu respeito, e você? Um dos organizadores desse evento na escola foi o professor das disciplinas de História e Sociologia, Renato Dória. Além de professor de História concursado do Estado do Rio de Janeiro, Dória faz parte do corpo discente da graduação de licenciatura em Ciências Sociais, pela Universidade Federal Fluminense e fez parte, no mesmo ano, do corpo estudantil do Curso de Comunicação Popular do Núcleo Piratininga de Comunicação.

No mesmo período fizemos um vídeo totalmente produzido pelo celular, chamado Quilombo do Camorim: Uma história de resistência ${ }^{19}$.O vídeo relata a abertura da sede da Associação Cultural Quilombo do Camorim, com uma atividade de celebração dentro da área correspondente ao Quilombo. Essa atividade foi organizada pela diretoria da ACUQCA em comemoração aos três anos de certificação de Comunidade Remanescente de Quilombo (CRQ) da Fundação Cultural Palmares. Os Quilombos do Camorim e Cafundá Astrogilda, de Vargem Grande, ambos em Jacarepaguá, receberam a certificação e o reconhecimento de sua herança histórico-cultural.

Devido a esse contato duplo com o professor Dória, tanto na Universidade, quanto no Curso de Comunicação Popular, recebi o convite para participar da feira ministrando a oficina de vídeo pelo celular. Assim, a pesquisa estava voltada para outro momento, agora na escola pública com funcionamento normal das atividades.

O C.E. Paulino Barbosa fica localizado no bairro de Santa Cecília, em Belford Roxo. Segundo o IDEB, o colégio possui 8 salas de aula, com 3 turnos de funcionamento e 24 turmas, com o pátio e a quadra de esportes descoberta. Oferecendo os anos finais do ensino fundamental, o ensino médio e EJA. O colégio não possui biblioteca, auditório,

\footnotetext{
19 Quilombo do Camorim: Uma história de resistência: Disponível em: <https://www.youtube.com/watch?v=e59lvyb-qYo>. Acesso em: 10 jun. 2019.
} 
Oficinas de vídeo pelo celular: o uso, a produção de vídeos e suas possibilidades de utilização como ferramenta pedagógica na educação básica. Revista Ensaios, vol. 15, jul-dez de 2019.

sala de leitura e laboratório de ciências. Mas possui uma sala que funciona como laboratório de informática, com computadores para uso dos alunos com acesso à internet.

O indicador de nível socioeconômicos $I N S E^{20}$ das escolas classifica em "grupo 3" o C.E. Paulino Barbosa. No indicador são classificadas as escolas em grupos, que variam de 1 a 6 , sendo o grupo 1 de alunos com baixo nível socioeconômico e o grupo 6 de alunos com alto nível socioeconômico. Os estudantes que se propuseram a participar da oficina, segundo o professor, estão em seu ciclo escolar, no caso o ensino médio e carregam com eles diversos dilemas desse período, como conseguir trabalho, concluir o período de formação e passar no vestibular.

A ideia inicial da oficina era capacitar os alunos para duas propostas de atividades. A primeira seria em 2017 e os estudantes fariam seus vídeos registrando a semana da consciência negra na escola. A segunda proposta seria no mês de abril de 2018 e os alunos registrariam o dia da Baixada Fluminense. Assim, nossa intenção era habilitar os alunos para esses dois momentos e projetos que a escola desenvolve nessas datas; elas fazem parte do calendário de atividades pedagógicas do ano letivo da Secretaria de Estado de Educação, também conhecido como SEEDUC.

O público da oficina se formou através de grupos de interesses. Os alunos foram passando de sala em sala divulgando a atividade duas semanas antes; a ideia de juntar todos possibilitou que outros alunos participassem da atividade. A maior parte, no entanto, eram do primeiro ano, mas compareceram alunos do segundo e do terceiro ano. Devido a um problema na organização da feira, não havia sala para iniciar a oficina e o colégio não tinha um auditório disponível, assim, a direção autorizou um espaço onde estavam guardados uma pilha de livros escolares e outros materiais para realização da atividade.

Nessas condições conseguimos dar início à oficina, com menos de 2 horas para ser efetuada e com cerca de 20 alunos. O objetivo era que os alunos compreendessem a

\footnotetext{
${ }^{20}$ O INSE tem o objetivo situar o conjunto dos alunos em estratos socioeconômicos, definidos pela posse de bens domésticos, renda e contratação de serviços pela família dos alunos e pelo nível de escolaridade de seus pais. Mais informações em: 〈http://idebescola.inep.gov.br/ideb/escola/dadosEscola/33047308>. Acesso em: 10 jun. 2019.
} 
Oficinas de vídeo pelo celular: o uso, a produção de vídeos e suas possibilidades de utilização como ferramenta pedagógica na educação básica. Revista Ensaios, vol. 15, jul-dez de 2019.

parte técnica da utilização do aparelho celular para produção dos vídeos. Enquanto aplicava as noções básicas de filmagem, iluminação e captação do som, e mostrava alguns acessórios para o celular, percebi uma euforia de parte dos alunos. Uma estudante disse "Agora vou virar youtuber 21 !", outros queriam que chegasse logo à parte de filmar. Percebi que a oficina despertava uma motivação para a aprendizagem pelos alunos.

Destaco que a mediação pedagógica do professor é muito importante para o encontro desses dois tipos de conhecimento, do uso do celular e do conhecimento escolar. Isso acontece a partir do desenvolvimento de novas práticas e metodologias de ensino. Quando falamos sobre o uso do celular em sala de aula, falamos de um novo componente dentro de sala, o que requer a ação de enxergar de outra forma. Pois a utilização das TICs, nesse caso, o celular, exige uma linguagem nessa produção que é diferenciada em relação à linguagem dos livros. Essa diferenciação deve ser considerada quando pensamos em nossas estratégias pedagógicas.

Dessa forma, podemos pensar essas estratégias a partir das perspectivas de uso de vídeos em aula utilizadas por Moran (1995, p. 30-31), ou seja, o vídeo como sensibilização: para introduzir um novo assunto, despertar a curiosidade e motivar os aluno; o vídeo como ilustração: como forma de apresentar cenários desconhecidos aos alunos; o vídeo como simulação: para mostrar, por meio de simulação, processos químicos, por exemplo; o vídeo como conteúdo de ensino: para informar sobre conteúdos específicos; o vídeo como produção: registro do trabalho desenvolvido, intervenção ou expressão.

Após essa primeira parte da oficina, fomos para parte prática. Os alunos aprenderam como fazer um suporte de câmera e de celular numa tampa de refrigerante e apresentei o aplicativo de edição de vídeos kinemaster. Alguns alunos já conheciam esse aplicativo, isso foi bom, pois facilitou a mediação de conhecimento sobre seu uso. No final, foi proposto que eles fizessem um pequeno vídeo de 3 a 5 minutos sobre a feira, entrevistando um aluno e um organizador da feira. Eles saíram para gravar, mas

\footnotetext{
${ }^{21}$ Celebridade e cinegrafista da internet que ganhou popularidade no site de compartilhamento de vídeos youtube. Disponível em: 〈https://pt.wikipedia.org/wiki/YouTuber〉. Acesso em: 10 jun. 2019.
} 
Oficinas de vídeo pelo celular: o uso, a produção de vídeos e suas possibilidades de utilização como ferramenta pedagógica na educação básica. Revista Ensaios, vol. 15, jul-dez de 2019.

infelizmente não conseguiram concluir o vídeo, pois o tempo de duração da oficina havia terminado.

Eles ficaram de elaborar três vídeos para novembro, na semana da consciência negra do colégio. Mas infelizmente esses vídeos não foram concluídos por eles. Havia uma dificuldade para conclusão dos vídeos: a feira era um evento esporádico dentro das atividades do colégio. Reunir os estudantes que eram de turmas e de séries diversas era muito difícil.

Assim, o professor e eu não conseguimos criar uma atividade extra-sala para dar continuidade ao processo dos vídeos e isso até o mês de novembro daquele ano. Um ponto de reflexão sobre esse momento foi que, além de existir uma dificuldade de introduzir o uso das TICs no ambiente escolar, existe um outro ponto a ser considerado que seria relativo aos estudantes sem aparelhos celulares. Por mais que boa parte dos alunos tenham um aparelho celular, é muito importante ressaltar que muitos adolescentes não têm acesso a um aparelho celular. E que as atividades precisam ser pensadas de modo a integrar o aluno sempre em grupos para beneficiá-lo com o conhecimento, apesar da privação material.

Pensar essas novas necessidades informacionais e novas formas de construção do conhecimento nos leva a refletir sobre hexis educativa. Para Muniz Sodré (2002), ela está sempre incorporando e modificando as tecnologias a partir de seu eixo temporal, sendo reestruturada e transformada de acordo com os aspectos políticos e econômicos vigentes, introduzindo de modo temporal e histórico os aspectos necessários para a formação de saberes.

Para pensarmos sobre o avanço das TICs e da necessidade de constante renovação da estrutura de trabalho e plano pedagógico do professor, Muniz Sodré (2002, pág. 95) chama atenção para as chamadas mutações pedagógicas. Para ele, isto tem total relação com a importância de reestruturar o sentido de revolução tecnológica para mutação tecnológica, a fim de levar em consideração o trânsito de informações e as constantes reintroduções de técnicas e formas de alocar e pensar os conteúdos pedagógicos. Pois não é possível pensar a educação, a partir dessa mutação tecnológica, 
Oficinas de vídeo pelo celular: o uso, a produção de vídeos e suas possibilidades de utilização como ferramenta pedagógica na educação básica. Revista Ensaios, vol. 15, jul-dez de 2019.

descolada dos processos midiáticos, já que elas estão a todo momento criando e renovando suas conexões em formas de construção de conhecimento.

É preciso, portanto, ampliar a noção da tecnologia educacional, que muitas das vezes marca somente os aspectos tecnicistas e privatistas da informação. Mas estabelecer um vínculo seguro entre apropriação e movimentação de conhecimento na medida em que ele mesmo muda sua forma de reintegrar a sociedade. E de forma a que os veículos que hoje tem sido fonte primária de informação pros jovens e adolescentes, como o celular, transformem-se também em aparelhos criadores de conhecimento, para receber e para deslocar saberes.

\section{4) Considerações finais:}

Durante a apresentação deste artigo apontei uma das possibilidades que as TICs apresentam para as práticas pedagógicas. A escola ainda não se encontra preparada para os jovens do século XXI e a utilização das TICs, no caso, os aparelhos celulares, permitem aos professores uma reflexão sobre suas práticas no dia a dia e, com isso, proporcionar uma nova maneira de aprendizagem para com os estudantes.

Uma vez que esses aparelhos estão inseridos na esfera social dessa juventude e são utilizados por eles de várias maneiras, como fotografia, gravações de vídeos, pesquisas pela internet, além do uso das redes sociais, o aparelho celular, por exemplo, pode atuar de maneira didática, ampliando o processo de interação entre professores e estudantes. Isso já acontece com a troca de informações através de mensagens de textos, de voz ou audiovisuais. Através das oficinas de vídeo produzidas pelo celular, quero possibilitar aos professores uma nova forma de atuar em sala de aula. Mas, para isso é necessária uma apropriação das técnicas de utilização dessas tecnologias, para depois incentivar e orientar os estudantes no uso desses aparelhos. Dessa forma, as Tecnologias da Informação e Comunicação podem ser incorporadas ao ambiente escolar, não como meros suportes ou ferramentas tecnológicas de ensino, mas como parte integrante do processo de ensinar.

Recebido em 20/11/2019. Aprovado em 17/05/2020

\section{Referências bibliográficas:}


Oficinas de vídeo pelo celular: o uso, a produção de vídeos e suas possibilidades de utilização como ferramenta pedagógica na educação básica. Revista Ensaios, vol. 15, jul-dez de 2019.

ALMEIDA, Geraldo Peçanha. Transposição didática: por onde começar?. São Paulo: Cortez, 2007.

BARRETO, Bruna A. L. Ocupar é resistir: um estudo sobre as ocupações secundaristas do Rio de Janeiro em 2016. Revista Em Debate (UFSC), Florianópolis, volume 16, p. 73-94, 2016. ISSNe 1980-3532.

COLL, César; MONEREO, Carles. Educação e aprendizagem no século XXI: novas ferramentas, novos cenários, novas finalidades. In: C. COLL; C. MONEREO (Org.), Psicologiadaeducação virtual - aprender e ensinar com as tecnologias da informação e da comunicação. Porto Alegre: Artmed, 2010.

DUARTE, Rosalia; ALEGRIA, João. Formação estética audiovisual: um outro olhar para o cinema a partir da educação. Educação \& Realidade, v.33, n1. Porto Alegre, jan./jun.2008.

FREIRE, Paulo. Pedagogia da Autonomia. Rio de Janeiro: Paz e Terra, 1996.

GIANNOTTI, Claudia Santiago. Experiências em comunicação popular no Rio de

Janeiro ontem e hoje: uma história de resistências nas favelas cariocas. Rio de Janeiro: Núcleo Piratininga de Comunicação/Fundação Rosa Luxemburgo, 2016.

LABRUNIE, Maria das Graças Lino; FERREIRA, Giselle Martins dos Santos Ferreira. O vídeo na escola: uma revisão de literatura. Revista Educação e Cultura Contemporânea, v. 15, n. 3, pp. 416-436. América do Norte, 1527012018.

MELLO, Maria Luzia Erthal. Tecnologias de informação e comunicação no ensino de sociologia das escolas públicas: técnicas pedagógicas para inclusão social. In: Queiroz, Paulo Pires de. O Ensino da Sociologia Escolar: O PIBID e a Formação de Professores, pp. 168-187, Rio de Janeiro: Autografia, 2017.

MORAN, J. M. O vídeo na sala de aula. In: Revista Comunicação \& Educação, São Paulo, ECA-Ed. Moderna, [2]: 27 a 35, jan./abr. 1995.

SODRÉ, Muniz. Antropológica do Espelho: Uma Teoria da Comunicação Linear e em Rede. Petrópolis: Editora Vozes. 2002.

\section{Referências videográficas:}

Canal do Youtube do Núcleo Piratininga de Comunicação - NPC. Disponível em: https://www.youtube.com/playlist?list=PL2OAzE7y8BOavbXXyPDvdpD4As8tuSY13

Filmes Produzidos com Celular por Eric Fenelon- Essa playlist é totalmente dedicada na realização de material audiovisual, que são captados, editados e finalizados em aparelho celular. Disponível em: https://www.youtube.com/playlist?list=PL2OAzE7y8BOYzK78xjel3_DH2UPkOne_n 
Oficinas de vídeo pelo celular: o uso, a produção de vídeos e suas possibilidades de utilização como ferramenta pedagógica na educação básica. Revista Ensaios, vol. 15, jul-dez de 2019.

Homenagem à Ocupação Manuel Congo. Disponível em: https://www.youtube.com/watch?v=xxqH5TbL99s

Morro do Bumba - Quatro Anos Depois. Disponível em: https://www.youtube.com/watch?v=vKkwuWjrPNA

Vila Recreio 2 - Sonhos Demolidos. Disponível em: https://www.youtube.com/watch?v=WM2iW6mIPWY

Sobrou Pra Quem?. Disponível em: https://www.youtube.com/watch?v=8utIzQnSikM

Comemorar o Que?. Disponível em: https://www.youtube.c om/watch?v=400L0GAf8zM

SMH - Saia do Morro Hoje. Disponível em:

https://www.youtube.com/watch?v=dPCkXlCMAok

Comunicação Popular no Rio: Quem faz. Disponível em:

https://www.youtube.com/watch?v=sSSFvoZzwdQ\&t=46s

Que é Ser Mulher?. Disponível em:

https://www.youtube.com/watch?v=dptfVSW4Ys0\&list=PL2OAzE7y8BOavbXXyPDv dpD4As8tuSY13\&index=23

Quilombo do Camorim: Uma história de resistência. Disponível em: https://www.youtube.com/watch?v=e59lvyb-qYo

Página do Youtube do Centro de Mídia Independente (CMI). Disponível em: https://www.youtube.com/user/midiaindependente/videos 